FOLIA POMERANAE UNIVERSITATIS TECHNOLOGIAE STETINENSIS

Folia Pomer. Univ. Technol. Stetin., Oeconomica 2018, 347(93)4, 69-76

Robert RUSIELIK

\title{
ZMIANY EFEKTYWNOŚCI TECHNICZNEJ ROLNICTWA W KRAJACH UNII EUROPEJSKIEJ W LATACH 2007-2016
}

\section{THE AGRICULTURE TECHNICAL EFFICIENCY CHANGE IN EUROPEAN UNION COUNTRIES IN YEARS 2007-2016}

Katedra Zarządzania Przedsiębiorstwami, Zachodniopomorski Uniwersytet Technologiczny w Szczecinie, ul. Klemensa Janickiego 31, 71-270 Szczecin, ORCID: 0000-0001-9821-4047 e-mail: robert.rusielik@zut.edu.pl

\begin{abstract}
Symmary. The aim of the research was the measure of agriculture technical efficiency in the European Union countries and the find level of differences in this efficiency over the analysed years. This study used the DEA (Data Envelopment Analysis) method and BCC input-oriented model with variable returns to scale. The results has shown that in analysed period efficiency indicators increased. However, the difference in the average level of efficiency between "old" and "new" EU member countries has decreased. Studies have also shown that the difference between the agricultural efficiency in Poland and the average EU efficiency increased.
\end{abstract}

Słowa kluczowe: rolnictwo, efektywność, DEA, EU.

Key words: agriculture, efficiency, DEA, EU.

\section{WSTĘP}

Efektywność rolnictwa uzależniona jest od wielu uwarunkowań - zarówno ekonomicznych, jak i społecznych. Uwarunkowania te podlegają ciągłym zmianom, co wpływa też na poziom efektywności w poszczególnych okresach. Badanie efektywności jest jednym z warunków w procesie dostosowania rozwoju rolnictwa do tych zmian i - co za tym idzie - do podniesienia poziomu konkurencyjności polskiego rolnictwa. Pomiar efektywności w przedstawionych badaniach ma charakter względny, tj. wynika z porównania krajów, w których rolnictwo uznano za efektywne, z krajami nieefektywnymi. Wyniki tego typu badań powinny interesować zarówno decydentów z zakresu kształtowania polityki rolnej, jak i uczestników tego sektora, uzupełniają bowiem ocenę rentowności, poziomu rozwoju i kondycji rolnictwa o miary efektywności wykorzystania czynników produkcji. Celem przeprowadzonych badań było określenie różnic w poziomie efektywności technicznej rolnictwa w krajach Unii Europejskiej. Wyniki pomiaru pozwolą na zbadanie, czy różnice te występują i jakie one są, a także stwierdzenie, czy zmieniły się one na przestrzeni lat 2007-2016.

\section{MATERIA I METODY}

Dane do badań uzyskano z bazy EUROSTAT. Dobór zmiennych do modelu został oparty na przeglądzie literatury. W celu zapewnienia spójności modelu zostały dobrane zmienne, które obejmują podstawowe czynniki produkcji w rolnictwie, tj. ziemię, kapitał i pracę. Dane 
pogrupowano w zestaw zmiennych, których kombinacja odzwierciedla technologię produkcji rolniczej. Do badań przyjęto następujący zestaw zmiennych: Y1 - produkcja rolnicza [mln EUR], X1 - powierzchnia użytków rolnych [tys. ha], X2 - praca [tys. AWU], X3 - koszty bezpośrednie [mln EUR], X4 - koszty ogólnogospodarcze i amortyzacja [mln EUR]. Koszty bezpośrednie (X3) obejmują: nasiona i sadzeniaki, nawozy, ochronę, weterynarię i pasze. Koszty obejmujące zmienną (X4) zawierają: energię, materiały, utrzymanie budynków, usługi rolnicze, amortyzację i inne koszty pośrednie. Podstawowe statystyki opisowe zmiennych przyjętych do modelu zamieszczono w tab. 1.

Tabela 1. Podstawowe statystyki opisowe zmiennych wykorzystanych w modelu

\begin{tabular}{|l|r|r|r|r|r|}
\hline \multicolumn{1}{|c|}{ Wyszczególnienie } & \multicolumn{1}{c|}{ Y1 } & \multicolumn{1}{c|}{ X1 } & \multicolumn{1}{c|}{ X2 } & \multicolumn{1}{c|}{ X3 } & \multicolumn{1}{c|}{ X4 } \\
\hline Min & 119,5 & 11,1 & 3,6 & 40,9 & 33,0 \\
\hline Max & 68166,6 & 29108,8 & 1963,3 & 24333,2 & 27011,7 \\
\hline Średnia & 13505,0 & 6434,8 & 374,3 & 4703,6 & 5376,4 \\
\hline Odch. stnd. & 17641,0 & 7593,8 & 504,8 & 6063,5 & 7031,2 \\
\hline
\end{tabular}

Źródło: na podstawie bazy danych EUROSTAT.

Z danych w tab. 1 wynika, że występuje duże zróżnicowanie pomiędzy poszczególnymi krajami pod względem skali działalności rolniczej. Przykładowo minimalna produkcja rolnicza w analizowanych krajach wyniosła 119,5 mln EUR (Malta), natomiast maksymalna - około 68 mld EUR. Efektem przeprowadzonej analizy zmiennych było między innymi przyjęcie do badań modelu, z jednej strony, zakładającego zmienne efekty skali (BCC), a z drugiej strony zorientowanego na nakłady. Orientacja modelu na nakłady jest zgodna z trendami w polityce zrównoważonego rozwoju Unii Europejskiej, która zakłada zwiększanie efektywności rolnictwa poprzez innowacje i dezintensyfikację nakładów (Bieńkowski i in. 2013). Z kolei Błażejczyk-Majka i in. (2011) uważają, że poprawa efektywności może następować poprzez zmniejszenie pracochłonności i równoczesne zmniejszanie zaangażowanego kapitału trwałego, przy jednoczesnym wzroście nakładów na postęp biologiczny, jak również techniczny i organizacyjny, co również jest zgodne z przyjętą orientacją modelu.

Analiza zmiennych i wstępna kalkulacja modeli wykluczyła z badań trzy kraje, tj. Cypr, Luksemburg i Maltę. Układ zmiennych w tych krajach nie był wystarczająco spójny z badaną grupą. Można uznać, że model działalności rolniczej w tych krajach jest zbyt odmienny, co podkreślali również Floriańczyk i Rembisz (2012), a także Baran (2016), w związku z czym nie mogą być one wg założeń metody DEA wykorzystane do porównań.

Do pomiaru efektywności wykorzystano założenia metody Data Envelopment Analysis (DEA), która jest metodą wielowymiarową i nieparametryczną. Metoda ta jest w coraz większym zakresie wykorzystywana do pomiaru efektywności rolnictwa. W literaturze krajowej znaleziono ponad 150 pozycji z tego zakresu. Dotyczą one głównie badania o zakresie regionalnym - na poziomie województw, gmin lub badania grup gospodarstw dobranych wg określonego kryterium. Mało jest krajowych badań dotyczących efektywności rolnictwa na poziomie Unii Europejskiej. Z tego zakresu badania prowadzili m.in. Baran (2016), Błażejczyk-Majka (2011, 2017), Kołodziejczak (2015), Staniszewski (2018). Publikowane badania różnią się głównie doborem zmiennych do modeli oraz założeniami dotyczącymi efektów skali. 
Metoda DEA oparta jest na koncepcji produktywności Debreu (1951) i Farrella (1957). Farrell stworzył koncepcję „granicy efektywności” lub „granicy produkcyjnej” (best practice frontier). Granica ta jest przyjmowana za technologiczną granicę możliwości produkcyjnych osiągalnych dla danej jednostki decyzyjnej (w naszym przypadku są to poszczególne kraje EU). Koncepcja Farrela zakładała pomiar efektywności danej jednostki decyzyjnej w relacji do innych jednostek z podobną technologią produkcji. Koncepcja ta z pojedynczego nakładu i pojedynczego efektu została rozwinięta do wielowymiarowych przypadków przez Charnesa, Coopera i Rhodesa (1978), którzy zaproponowali model zakładający stałe efekty skali nazywamy najczęściej w literaturze modelem CCR. Wraz z rozwojem badań wykorzystujących założenia tej metody stworzono wiele alternatywnych modeli i modyfikacji podstawowego modelu CCR. Jak wspomniano wyżej w badaniach wykorzystano zorientowany na nakłady model BCC zakładający zmienne efekty skali (Banker i in. 1984).

Koncepcja pomiaru efektywności zastosowana w modelach CCR i BCC wykorzystuje jedną z najbardziej popularnych technik opisanych m.in. w pracy „Production Frontiers” (Färe i in. 1995). Dysponując s-efektami i m-nakładami, efektywność techniczną można obliczyć z równania (1):

$$
\frac{\sum_{r=1}^{s} u_{r} y_{r}}{\sum_{i=1}^{m} v_{i} x_{i}}=\frac{u_{1} y_{1}+u_{2} y_{2}+\ldots \ldots+u_{s} y_{s}}{v_{1} x_{1}+v_{2} x_{2}+\ldots \ldots .+v_{m} x_{m}}
$$

gdzie:

$y_{r}$ - wartość efektu,

$u_{r}$ - waga efektu,

$x_{i}$ - wartość nakładu,

$v_{i}$ - waga nakładu.

Dla każdego obiektu jest rozwiązywane zadanie programowania liniowego, w którym obliczany współczynnik efektywności ma postać funkcji celu poddanej maksymalizacji, a zmiennymi optymalizowanymi są wagi efektów i wagi nakładów. Dla modeli zorientowanych na nakłady w postaci dualnej przyjmuje ono postać (2):

$\min \Theta$

$\Theta, \lambda$

przy ograniczeniach (3):

$$
\begin{aligned}
& \mathbf{Y} \boldsymbol{\lambda} \geq \mathbf{Y}_{\mathbf{o}} \\
& \Theta \mathbf{X}_{\mathbf{o}}-\mathbf{X} \boldsymbol{\lambda} \geq 0
\end{aligned}
$$

$\lambda \geq 0$

gdzie:

$\mathbf{X}_{\boldsymbol{o}}$ - wektor nakładów danego obiektu (o wymiarach $[1 \times m]$ ),

$\mathbf{X}$ - macierz nakładów wszystkich obiektów (o wymiarach $[n \times m]$ ),

$\mathbf{Y}_{\mathbf{0}}$ - wektor efektów danego obiektu (o wymiarach [1 $\left.\times s\right]$ ),

$\mathbf{Y}$ - macierz efektów wszystkich obiektów (o wymiarach $[n \times s]$ ),

$\lambda_{1}, \ldots, \lambda_{\sigma}-$ współczynniki kombinacji liniowej,

$\Theta-$ współczynnik efektywności obiektu.

Zadanie to jest rozwiązywalne dla wszystkich $n$ obiektów, natomiast celem optymalizacji w przedstawionym modelu jest znalezienie minimalnej wartości $\Theta$, przy której możliwe jest zredukowanie nakładów lub wykorzystywanych zasobów, umożliwiające osiągnięcie 
niezmienionego poziomu efektu. Gdy nie jest możliwe znalezienie takiej wartości, wówczas $\Theta=1$, co oznacza, że nie istnieje bardziej korzystna kombinacja, pozwalająca na osiągnięcie przez obiekt tych samych efektów. O obiekcie mówimy wtedy, że jest ekonomicznie efektywny. Natomiast, gdy $\Theta<1$, istnieje bardziej efektywna kombinacja nakładów umożliwiająca osiągnięcie tych samych efektów. Parametr $\Theta$ określa, jaki procent nakładów badanego obiektu jest wystarczający do osiągnięcia obecnego poziomu efektów, przy wykorzystaniu technologii obiektów efektywnych. Informacji o strukturze optymalnej kombinacji nakładów i efektów dostarczają współczynniki kombinacji liniowej $\lambda$ (Rusielik 2017).

Banker, Charnes i Cooper w 1984 roku zaproponowali rozszerzenie modelu CCR do modelu BCC zakładającego zmienne efekty skali (Banker i in. 1984). W tym celu model CCR można zmodyfikować poprzez dodanie ograniczenia wypukłości $1 \cdot \lambda=1$, co daje $w$ efekcie model w postaci (4):

$\min \Theta$

przy ograniczeniach (5):

$$
\begin{aligned}
& \mathbf{Y} \boldsymbol{\lambda} \geq \mathbf{Y}_{\mathbf{0}} \\
& \Theta \mathbf{X}_{\mathbf{o}}-\mathbf{X} \boldsymbol{\lambda} \geq 0 \\
& \mathbf{1} \cdot \boldsymbol{\lambda}=1 \quad \boldsymbol{\lambda} \geq 0
\end{aligned}
$$

Takie założenie powoduje, że w tym modelu wyniki efektywności są bardziej precyzyjne niż wyniki uzyskane przy założeniu CCR.

\section{WYNIKI}

W analizowanej grupie państw obliczono wskaźniki efektywności technicznej dla modelu zakładającego zmienne efekty skali BCC. Na potrzeby porównań, obliczenia obejmowały trzy okresy, tj. rok 2007, rok 2011 i rok 2016. Syntetyczne wyniki pomiaru, wraz z podstawową statystyką dla całej grupy krajów przyjętych do porównań, przedstawiono w tab. 2.

\begin{tabular}{|c|c|c|c|}
\hline Wyszczególnienie & 2007 & 2011 & 2016 \\
\hline Liczba krajów & 25 & 25 & 25 \\
\hline Średnia & 88,6 & 93,8 & 92,8 \\
\hline Minimum & 70,9 & 78,7 & 74,0 \\
\hline Maksimum & 100,0 & 100,0 & 100,0 \\
\hline Odchylenie standardowe & 10,4 & 6,9 & 7,7 \\
\hline $25 \%$ & 81,5 & 86,7 & 86,5 \\
\hline $50 \%$ & 83,7 & 97,3 & 94,0 \\
\hline $75 \%$ & 100,0 & 100,0 & 100,0 \\
\hline Kraje efektywne & 9 & 11 & 12 \\
\hline
\end{tabular}

Tabela 2. Średnia efektywność techniczna działalności rolniczej w wybranych krajach Unii Europejskiej w latach 2007, 2011 i 2016

Najniższy średni poziom efektywności odnotowano w roku 2007. W tym roku największe też było zróżnicowanie pomiędzy poszczególnymi krajami. Najwyższy poziom wskaźników efektywności odnotowano w roku 2011; w roku 2016 był on o około 1\% niższy. Można również zauważyć, że rośnie liczba krajów uznanych za efektywne - z 9 w roku 2011 do 12 w roku 2016. 
Wskaźniki efektywności technicznej dla poszczególnych krajów zamieszczono w tab. 3. Analiza poziomu wskaźników efektywności wykazała, że w badanej grupie jest 8 krajów, które we wszystkich analizowanych latach wykazały się efektywnością; są to: Belgia, Dania, Estonia, Francja, Grecja, Włochy, Holandia, Słowenia i Hiszpania. Trzy kraje, tj. Chorwacja, Bułgaria i Niemcy, dołączyły do grupy krajów efektywnych w roku 2011 lub 2016. Pozostałe analizowane kraje wykazały się we wszystkich analizowanych latach pewnym poziomem nieefektywności. W roku 2007 do krajów o najniższej efektywności rolnictwa można było zaliczyć Węgry (70,9\%), Rumunię (72,4\%) i Czechy (73,0\%). W roku 2011 do grupy tej można było zaliczyć Finlandię (78,7\%), Irlandię (81,4\%), Portugalię i Czechy $(85,1 \%)$. Z kolei w roku 2016 do grupy tej zaliczono Finlandię $(74,0 \%)$, Irlandię $(82,4 \%)$ i Litwę $(82,9 \%)$.

Tabela 3. Efektywność techniczna rolnictwa w krajach Unii Europejskiej w latach 2007, 2011 i 2016

\begin{tabular}{|c|c|c|c|}
\hline & 2007 & 2011 & 2016 \\
\hline Austria & 88,8 & 94,8 & 88,9 \\
\hline Belgia & 100,0 & 100,0 & 100,0 \\
\hline Dania & 100,0 & 100,0 & 100,0 \\
\hline Finlandia & 81,4 & 78,7 & 74,0 \\
\hline Francja & 100,0 & 100,0 & 100,0 \\
\hline Niemcy & 99,4 & 100,0 & 100,0 \\
\hline Grecja & 100,0 & 100,0 & 100,0 \\
\hline Irlandia & 77,4 & 81,4 & 82,4 \\
\hline Włochy & 100,0 & 100,0 & 100,0 \\
\hline Holandia & 100,0 & 100,0 & 100,0 \\
\hline Portugalia & 81,8 & 85,1 & 86,5 \\
\hline Hiszpania & 100,0 & 100,0 & 100,0 \\
\hline Szwecja & 83,5 & 92,2 & 90,6 \\
\hline Wielka Brytania & 81,5 & 97,3 & 87,2 \\
\hline Bułgaria & 83,7 & 91,5 & 100,0 \\
\hline Chorwacja & 95,7 & 100,0 & 100,0 \\
\hline Czechy & 73,0 & 85,1 & 84,6 \\
\hline Estonia & 100,0 & 100,0 & 100,0 \\
\hline Węgry & 70,9 & 85,4 & 88,4 \\
\hline Łotwa & 83,4 & 86,7 & 94,0 \\
\hline Litwa & 81,9 & 85,4 & 82,9 \\
\hline Polska & 83,2 & 92,0 & 86,4 \\
\hline Rumunia & 72,4 & 90,7 & 83,7 \\
\hline Słowacja & 76,5 & 98,5 & 91,3 \\
\hline Słowenia & 100,0 & 100,0 & 100,0 \\
\hline Średnia EU-28* & 88,6 & 93,8 & 92,8 \\
\hline Średnia EU-15 & 92,4 & 95,0 & 93,5 \\
\hline Średnia EU-13 & 83,7 & 92,3 & 91,9 \\
\hline Minimum & 70,9 & 78,7 & 74,0 \\
\hline
\end{tabular}

* wykluczono kraje: Cypr, Luxemburg, Malta. Pogrubioną czcionką oznaczono kraje efektywne.

W roku 2007 wartość pierwszego kwartyla wynosiła 81,5\%, w roku 2011 wzrosła do 86,7\% a w roku 2016 nieznacznie spadła - do 86,5\%. Zmienił się też układ krajów w analizowanym kwartylu. Czechy, Finlandia, Irlandia i Wielka Brytania występowały stale w tej grupie. W roku 2007 możemy wyróżnić Węgry, Rumunię i Słowację, w roku 2011 - Węgry, Łotwę, Litwę i Portugalię, natomiast w roku 2016 - Litwę, Polskę Portugalię i Rumunię.

Można także zauważyć, że oprócz jednego przypadku (Finlandia), poziom wskaźników efektywności w roku 2011 wzrósł, w porównaniu z rokiem 2007. Z kolei w roku 2016 w porównaniu z rokiem 2011, kilka krajów zwiększyło, a kilka zmniejszyło poziom wskaźnika efektywności. Największą dodatnią dynamikę zmian w analizowanych latach odnotowano 
w Bułgarii, na Węgrzech, w Łotwie, Irlandii i Portugalii. W krajach tych poziom analizowanego wskaźnika rośnie. W Finlandii odnotowano spadek efektywności rolnictwa z 81,4\% w roku 2007 do $74,0 \%$ w roku 2016. Był to jedyny kraj, w którym poziom efektywności stale się zmniejszał, w porównaniu z rokiem 2007.

W następnym etapie badań przeprowadzono analizę różnic w poziomie efektywności technicznej krajów z tzw. starej Unii (EU-15) i nowych krajów członkowskich EU-13. Jak wyżej napisano z badań zostały wykluczone trzy kraje, tj. Cypr, Luxemburg i Malta. We wszystkich analizowanych latach poziom efektywności technicznej w krajach EU-15 był wyższy niż w krajach EU-13. Wśród krajów EU-15 do krajów efektywnych możemy zaliczyć Belgię, Danię, Francję, Niemcy, Grecję, Włochy, Holandię i Hiszpanię. Z kolei w śród nowych krajów członkowskich za efektywne można uznać tylko Estonię i Słowenię, a w następnych latach - Chorwację i Bułgarię. Pozostałe kraje w całym analizowanym okresie były nieefektywne. Można jednak zauważyć tendencję malejącą w różnicy średniego poziomu efektywności pomiędzy „starymi” a „nowymi” krajami członkowskimi. W roku 2007 różnica ta wynosiła około $8,7 \%$, a w roku 2016 - tylko $1,6 \%$. Wskazuje to na zmniejszające się dysproporcje pomiędzy nakładami i efektami produkcji rolniczej pomiędzy poszczególnymi krajami.

Analizując efektywność działalności rolniczej w Polsce na tle pozostałych krajów EU, można stwierdzić, że we wszystkich analizowanych okresach poziom efektywności kształtował się poniżej średniej europejskiej. Największą różnicę odnotowano w roku 2016 - wyniosła ona ponad 6\%. Najwyższy poziom efektywności w Polsce (92\%) odnotowano w roku 2011.

\section{WNIOSKI}

Obliczono wskaźniki efektywności technicznej krajów Unii Europejskiej dla lat 2007, 2011 i 2016. Do badań przyjęto model zakładający zmienne efekty skali BCC. Badania wykazały, że średni poziom efektywności technicznej w krajach EU wzrósł o ponad 4\%.

$\mathrm{Na}$ podstawie badań można wyróżnić grupę krajów stale efektywnych, są to: Belgia, Dania, Estonia, Francja, Grecja, Włochy, Holandia, Słowenia i Hiszpania. Do krajów tych dołączyły Chorwacja, Bułgaria i Niemcy.

Do krajów o najniższej efektywności rolnictwa można zaliczyć takie kraje, jak: Finlandia, Irlandia, Czechy i Litwa.

W badanych latach wskaźniki poziomu efektywności rolnictwa w poszczególnych krajach rosły; jedynie w przypadku Finlandii wskaźniki te malały. Wskazuje to na zmniejszające się dysproporcje pomiędzy analizowanymi nakładami i efektami produkcji rolniczej pomiędzy krajami członkowskimi.

Można stwierdzić, że występują wyraźne różnice w średnim poziomie efektywności rolnictwa w krajach „starej” Unii i „nowej” Unii. Jednocześnie można stwierdzić, że różnice te w badanych latach malały. $Z$ nowych krajów członkowskich za efektywne można uznać Estonię i Słowenię.

Mimo że poziom efektywności rolnictwa w Polsce rośnie, kształtuje się on poniżej średniej dla EU. Oprócz tego różnica pomiędzy średnią EU a poziomem efektywności rolnictwa w Polsce wzrosła. 


\section{PIŚMIENNICTWO}

Banker R.D., Charnes A., Cooper. W.W. 1984. Some models for estimating technical and scale inefficiency in Data Envelopment Analysis. Manag. Sci. 30,1078-1092,

Baran J. 2016. Efektywność polskiego rolnictwa na tle pozostałych krajów Unii Europejskiej. Wieś Roln. 3(172), 63-85.

Bieńkowski F., Jankowiak J., Dąbrowicz R., Halka M. 2013. Porównanie produkcyjności ogólnej polskiego rolnictwa na tle krajów Unii Europejskiej. Rocz. Nauk. SERiA 15(2), 35-40.

Błażejczyk-Majka L. 2017. Application of dea for evaluating the efficiency of economic policy as exemplified by EU agriculture. Stud. Hist. Oeconom. UAM 35, 163-176.

Blażejczyk-Majka L., Kala R., Maciejewski K. 2011. Efektywność produkcji rolniczej na obszarze Unii Europejskiej w latach 1989-2007. Zesz. Nauk. SGGW, Problemy Rolnictwa Światowego 11(26)1, 28-38.

Charnes A., Cooper W.W., Rhodes E. 1978. Measuring the efficiency of decision making units. Eur. J. Operat. Res. 2(6), 429-444.

Debreu G. 1951. The Coefficient of Recourse Utilisation. Econometrica 19(3), 273-292.

Färe R., Grosskopf S., Lovell A.K. 1995. Production Frontiers. Cambridge, Cambridge University Press.

Farrell M.J. 1957. The measurement of productive efficiency. J. Royal Stat. Soc., Ser. A 120(3), 253-281.

Floriańczyk Z., Rembisz W. 2012. Dochodowość a produktywność rolnictwa polskiego na tle rolnictwa unijnego w latach 2002-2010. Problemy rolnictwa Światowego. Zesz. Nauk. SGGW 12(1), 56.

Kołodziejczak M. 2015. Efektywność wykorzystania czynników produkcji w rolnictwie polskim na tle unii europejskiej. Wieś Roln. 2(167), 169-192.

Rusielik R. 2017. Skala a efektywność techniczna produkcji trzody chlewnej, w: Wyzwania na rynku żywca wieprzowego w Polsce. Warszawa, Wydaw. SGGW, 69-78.

Staniszewski J. 2018. Wpływ struktur wytwórczych na zrównoważoną intensyfikację produkcji rolnej w krajach Unii Europejskiej po 2004 roku. Praca doktorska. Uniwersytet Ekonomiczny w Poznaniu (niepublikowana).

Streszczenie. Głównym celem badań był pomiar efektywności rolnictwa w krajach Unii Europejskie i znalezienie różnic $w$ jej poziomie $w$ badanych latach. $W$ badaniach uwzględniono założenia metody Data Envelopment Analysis (DEA). Do obliczeń wykorzystano model zakładający zmienne efekty skali (BCC), zorientowany na nakłady. Badania wykazały, że poziom wskaźników efektywności w badanych latach wzrósł. Zmniejszyła się różnica w średnim poziomie efektywności pomiędzy krajami „starej” EU a „nowymi” krajami członkowskimi. Zwiększyła się natomiast różnica pomiędzy efektywnością rolnictwa w Polsce a średnią efektywnością EU. 
